\title{
The Effects of Mental Math Strategies on Pre-service Teachers' Self-awareness and Computational Skills
}

\author{
Sayonita Ghosh Hajra \\ University of Utah \\ Victoria Kofman \\ Stella Academy
}

The purpose of the study is to examine and proliferate pre-service teachers' understanding of mental addition and subtraction and prepare them for teaching these topics to their students. Thirty-one elementary pre-service teachers enrolled in two sections of an arithmetic course at a public university in the United States of America, participated in a semester long study. A mental math strategies program, lasting 10 minutes of each class period, was implemented with the treatment group consisting of seventeen pre-service teachers. The control group was taught the same material excluding the mental math strategies program. Both groups' strategies for solving one-step wholenumber problems and the pre-service teachers' capacity to analyze their own strategies were examined. Results suggested pre-service teachers (both treatment and control) lacked knowledge for effective mental math strategies and were sometimes unaware of the strategies they used. This study presents novel approaches for improving pre-service teachers' mental math computational awareness and skills. The results of the study suggest investing time in teaching the ideas of mental math to pre-service teachers to help them attain fluency.

Keywords: Active strategies, arithmetic, mental math, pre-service teachers, variations.

With the Common Core State Standards for Mathematics (CCSSM) (National Governors Association for Best Practices, Council of Chief State School Officers [NGA \& CCSSO], 2010) accepted in most U.S. states, strategies that ensure students' flexibility with their problem-solving approaches have become a necessary attribute of learning (Price, Mazzocco, \& Ansari, 2013; Tsao, 2011). This increased role of mental computations is believed to promote conceptual understanding (McIntosh \& Dole, 2000; Reys \& Barger, 1994). Mental computation strategies require deep knowledge of mathematics (Heirdsfield \& Cooper, 2002) and often provide early approximation to the correct answer (Plunkett, 1979). The current authors distinguish active mental math strategies from paper-and-pen algorithmic calculations even if they are performed mentally. The authors consider paper- 


The current authors' hypothesis corroborated with studies of Şengül (2013) and Young-Loveridge, Bicknell, and Mills (2012) who found the number sense of pre-service teachers was very low internationally, particularly with problems involving fractions and decimals. The current authors speculated these deficiencies were rooted in insufficient mathematics skills on a much lower level. Yang (2007) recommended training programs should focus on developing computation and estimation skills of elementary school teachers who were responsible for developing children's number sense (Fung \& Latulippe, 2010). Such training is necessary because mathematics teachers' obligation to the discipline increases when their mathematics-content knowledge is higher (Shultz \& Herbst, 2016).

This study aims to improve pre-service teachers' knowledge regarding mental computations and to prepare them for teaching this topic to their future students. Hence the research questions are: how proficient are pre-service teachers at active mental math, and how can we improve their performance?

\section{Theoretical Framework}

In contrast with research (Heirdsfield, 2003) which states, students must not be taught active mental math strategies since they discover these strategies by themselves, many countries teach mental math strategies via class discussion or lecture and students are expected to explain the strategies they used verbally or in writing (Arginskaya, 1998; Peterson, 2006; Primary Mathematics 2B Textbook, 2003). To introduce the strategies, number lines, base-ten manipulatives, their pictorial representations, and/or a picture of $10 \times 10$-board are usually used in various countries (Arginskaya, 1998; Beishuizen, 1993). In the United States of America, a similar approach was recently proposed with a strong emphasis on whole-class discussion and concurrent usage of pictures, number lines, and Montessori 100-board. Application of this approach results in co-construction of mental math strategies by a "community of learners" (Heirdsfield \& Lamb, 2006).

As discussed in Heirdsfield (2003), Vygotsky's zone of proximal development (ZPD) "was considered an important aspect of qualitative assessment of children's mental addition and subtraction proficiency" (p. 57). The current authors believe some students might have ZPD, which does not allow them to get all benefits when using models. Those students first must develop an understanding of mental math strategies using a realistic, hands-on approach. Base-10 manipulatives help develop necessary ZPD needed for using models.

To meet the needs of students with various ZPDs, the authors create an environment where students develop their own prerequisite experiences, individually discover new knowledge, and solve specially designed number problems to internalize this knowledge. To meet the first goal, the authors use base-ten manipulatives allowing each student to obtain individual, hands-on experience with addition and subtraction (see Figure 1) and create an environment 

time (see examples in Table 2) while ideas were validated through handson experience.

b) Students used manipulatives and pictures to solve problems in a prepared environment - the best strategies became obvious to the students who used provided base-ten manipulatives.

c) Guided questions framed students toward discovery (Vygotsky, 1978; Wood, Bruner, \& Ross, 1976).

d) Contrasting variations (Marton, 2015) were applied to stimulate learning.

e) Direct instruction (Magliaro, Lockee, \& Burton, 2005) was used to facilitate translation of hands-on strategies into mathematical language.

Direct instruction was used only for translation and only self-discovery was used for creating novel procedures. Without such instruction, the base-10, hands-on approach would result in a "pseudo-effect." According to research by Beishuizen (1993), when students were not translating each step into mathematical language, despite their success with manipulatives, students did not translate hands-on mental math manipulations into mental computations.

\section{Methodology}

\section{Participants and Course Materials}

Participants of this study were thirty-one elementary pre-service teachers from a western public university enrolled in two sections of an arithmetic four-credit course. The lead author was the instructor for the treatment group consisting of one section with 17 pre-service teachers. The remaining 14 participants were the control group. A different instructor taught these participants. The treatment group met two days per week for 2 hours a day. The control group met three days per week for 1 hour and 20 minutes a day.

The same standard course textbook was used for both groups with an additional mental math strategies program provided only to the treatment group. The second author developed the mental math strategies program (MSP) for remediation and enrichment of $2^{\text {nd }}$ to $7^{\text {th }}$ grade students for a learning center in the Midwest U.S. The lead author used 10 minutes from each class to work on MSP for addition and subtraction, utilizing base-ten manipulatives (see Figures 1,3 ) for most of the lessons.

Materials: pennies or plastic coins, plastic boxes that can hold 10 coins, a colored rectangular sheet of paper (counting chart). The chart is subdivided into three equal parts using two parallel lines.

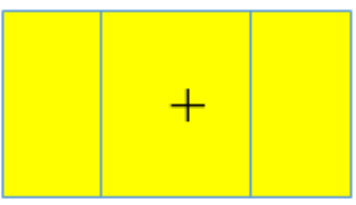

Counting Chart

Figure 3. Materials needed for activities. 

Table 2

Some of the Topics on Mental Math

\begin{tabular}{|c|c|}
\hline & Lessons \\
\hline 1. & $\begin{array}{l}\text { Building numbers using base-ten } \\
\text { manipulatives. }\end{array}$ \\
\hline & $\begin{array}{l}\text { Separation strategy of addition } \\
\text { and subtraction using base-ten } \\
\text { manipulatives. }\end{array}$ \\
\hline & $\begin{array}{l}\text { Close the box method for addition } \\
\text { to understand adding to ten. } \\
\text { (Mixed) }\end{array}$ \\
\hline & $\begin{array}{l}\text { Separation of ten method. Use } \\
\text { base-ten manipulatives to develop } \\
\text { strategy for solving } 40-6 \text { and } 150 \\
-7 \text { problems. }\end{array}$ \\
\hline
\end{tabular}

5. Empty the box method for mental subtraction. (Mixed)

6. Complementary Addition method for subtraction of big numbers.
Examples
Represent 26 as two closed boxes of
ten and additional 6 coins.
Perform addition, $23+45$ using boxes
of tens and coins. Perform subtraction,
$45-23$, using boxes of tens and coins.

Add $38+7$ by manually adding coins into the box with 7 coins. Writing $38+$ $7=40+5=45$.

Translate manual actions onto symbolic language for the problems like $40-6=30+4=34$. Extend experience to solve more complex problems: $150-7=140+3=143$. Subtract, 35-7 using manipulatives. Present manual steps using identical transformations: $35-7=30-2=$ 28.

$51-49=$ ? presented as $49+\ldots=51$. Here, students count from 49 to 51 and write what is needed to reach 51 .

Note. The grey row is discussed in detail in Figure 4.

After the mid-term test, daily homework, 100-120 multi-digit addition/subtraction problems, was assigned weekly for four weeks. A post-test was administered to both the control and treatment groups. It consisted of a 3minute timed test of 3 and 4-digit addition/subtraction problems (20 problems) and a timed 5-minute strategies' explanation. During the 3-minute test, preservice teachers were asked to write their answers. During the 5-minute task, the participants explained their strategies for six multi-digit additionsubtraction problems.

All written data was digitized. A spreadsheet of the pre-service teachers' written responses to each task was created to trace an individual pre-service teacher's progress across tasks and simultaneously compare their responses over time. The experimental data were analyzed quantitatively.

\section{Results}

\section{Pre-service Teachers' Mental Math Flexibility}

Four timed pre-tests, conducted with treatment group, captured preservice teachers' mental math strategies. Below, the results of four pre-tests, which examined pre-service teachers' readiness in terms of active mental 

The current authors argue the inconsistency between calculations and the chosen strategies did not depend on the multiple-choice test layout or inattentiveness. Most of the answers were not chosen arbitrarily; on similar problems, the participants consistently chose similar strategies. Therefore, it was concluded, the discrepancies between the methods applied and the strategies selected were due to pre-service teachers' insufficient knowledge regarding the methods used.

Many of the students performed two-digit addition/subtraction mentally on pre-test 3, but could not mentally solve problems involving multi-digit problems that could have been easily solved using active mental math strategies. Fifteen out of 17 pre-service teachers used only standard algorithms for 4-digit subtraction and addition (Figure 6) while the problems could have been solved effectively using compensation, $4612-2997=4612-3000+3=$ $1612+3=1615 ; 5894+1998=5894+2000-2=7894-2=7892$.

Figure 6. Work by a pre-service teacher on 4-digit subtraction and 4-digit addition.

On pre-test 4 , only 13 out of 17 students were present in-class. Only one student used a mental math strategy-separation method, to solve most of the problems, while seven out of 13 students used the algorithmic method for all problems but two. Those two exceptional problems, 692-689 and 471-467, required complementary addition. The rest of the students, 5(13), used algorithmic methods for all problems. At least 8 of 17 pre-service teachers demonstrated competency with complementary addition, 5 did not use complementary addition, and 4 were absent in the day of pre-test 4 .

\section{Intermediate Progress after Mid-semester Treatment}

Analyzing the mid-term data from the treatment group, it was observed, the pre-service teachers continued to struggle with problems like $60-8$ and $150-7$. They could not solve these problems fluently even after the lessons where they constructed the strategy of "separation of 10 " and had some practice with this method.

Mid-term data also suggested a prepared environment and scaffolding helped most of the pre-service teachers construct the efficient methods for addition and subtraction. It included separation, aggregation, and compensation strategies (Figure 7). However, the pre-service teachers needed additional practice with novel strategies to become accustomed to the ideas of mental math. 


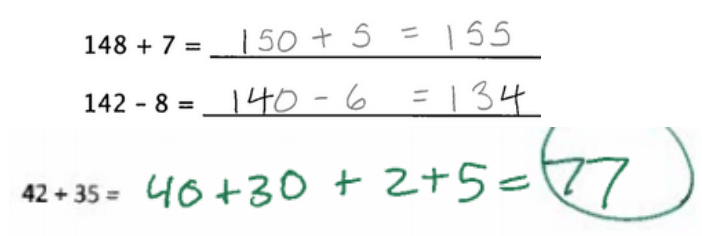

Figure 7. Pre-service teachers' work on mental math strategies.

Providing feedback in the mid-term test, one pre-service teacher wrote, "Because, they [the methods of calculations] are different than what is always done, so it's a new concept to me." Another wrote "I understand it while we are doing it, but then because I haven't practiced, I don't remember." The average correct response in the mid-term test (5-minute mental math test) was 51 problems out of 80 . Unfortunately, the current authors could not compare the results with the pre-test 1 , since the pre-test 1 contained all four arithmetic operations. At the beginning of the study, the researchers wanted to teach calculations involving 3-4 digit positive numbers and include topics on multiplication and division. However, they found, pre-service teachers, who participated in the study, were not fluent with active mental math strategies for addition and subtraction of two-digit numbers.

As it was discovered on the mid-term test, the pre-service teachers' awareness toward mental math increased significantly; 16 of 17 pre-service teachers expressed interest in learning mental math strategies. The study participants started to analyze their calculations and recognized better alternatives to their strategies. Meanwhile, 10 of 17 pre-service teachers admitted they needed more practice to achieve fluency.

\section{Pre-service Teachers' Progress after Treatment}

In the post-test, pre-service teachers showed improvement in the use of mental math strategies. Thirteen pre-service teachers from the treatment group used active mental math strategies while all 16 students from the control group used a passive strategy - standard algorithms (Figure 8). In spite of this, the treatment group's results were somewhat lower than the control group on the timed post-test with 3-4 digit addition and subtraction problems. On average, the treatment group students solved 8.4 out of 20 problems correctly while the control group solved 8.7 problems correctly.

Table 3 demonstrates pre-service teachers' (treatment group) use of mental math strategies after instruction. The table demonstrates that after the treatment, fifteen out of 17 used mental math strategies and two used only algorithmic calculations. There is not enough evidence to say, in all cases, students applied the best strategy in terms of working memory use. 

applied and the strategies they utilized were found. Based on this, the current authors argued, the reason behind low proficiency and low flexibility with mental techniques was an insufficient metacognitive awareness regarding the variety of mental math approaches. Hence, the authors concluded, pre-service teachers must be helped in constructing active mental math strategies and attaining flexibility and fluency when using them.

On a small sample of 31 students, it was found, with an exception of complementary addition strategy, most teacher candidates did not construct their own mental math strategies throughout their school years but have shown high proficiency with algorithmic calculations. Therefore, if it is expected from elementary teachers to come to schools and help children develop flexibility with mental math strategies, teachers' educators must assure the teachers are aware of these active mental math strategies. The current authors believe the poor situation with mental math can be improved using supplementary arithmetic instruction based on an application of Martin and Pang's contrasting variations (2006). In accordance with this theory, students are placed in an environment prompting them to "construct" each strategy and internalize it by solving problems using contrasting strategies (contrasting variations).

In an ideal case, students would construct new strategies themselves or with very little help. However, most pre-service teachers were not new to the idea of regrouping. Therefore, in many cases, the teacher candidates enforced the knowledge of familiar concepts instead of constructing new knowledge. Despite this limitation, a huge leap in the pre-service teachers' mental math appreciation, as well as with their engagement with the strategies was detected after only a few weeks of 10 minutes-per-lesson instructions. This progress demonstrated, direct instruction with translating "hands-on" strategies into mathematical equations helped pre-service teachers avoid the "pseudo-effect" described by Beishuizen (1993) and transformed their "hands-on" manipulations into analogous mathematical calculations.

Nevertheless, as the mid-term test demonstrated, constructing new knowledge followed by 5-minute in-class practice is insufficient to change students' habits of calculation using passive algorithmic strategies. The current authors' experience (unpublished results) shows that all students, who have sufficient practice with variations, develop complete proficiency with active mental math strategies. Heirdsfield (2003) found, young students did not need to be taught active mental math strategies but "merely encouraged to develop and use efficient strategies" (p. 60). However, current research with adult students demonstrated otherwise. With minor exemptions, study participants customarily used the algorithmic approach and did not develop effective approaches for arithmetic calculations. The mid-term test showed that an encouragement and help with "constructing" more productive (in terms of working memory usage) approaches resulted in minor progress with strategies application.

Therefore, after the mid-term, the authors adjusted their approach by 

elementary program. Samara, Russia: Fedorov Corporation. [In Russian]

Beishuizen, M. (1993). Mental strategies and materials or models for addition and subtraction up to 100 in Dutch second grades. Journal for Research in Mathematics Education, 24(4), 294-323.

Bofferding, L., Farmer, S., Aqazade, M., \& Dickman, K. (2016). Developing quantitative reasoning in word problems. In M. B. Wood, E. E. Turner, M. Civil, \& J. A. Eli (Eds.). Proceedings of the 38th annual meeting of the North American Chapter of the International Group for the Psychology of Mathematics Education (p. 203). Tucson, AZ: The University of Arizona.

Carpenter, T. P., Franke, M. L., Jacobs, V. R., Fennema, E., \& Empson, S. B. (1997). A longitudinal study of invention and understanding in children's multi-digit addition and subtraction. Journal for Research in Mathematics Education, 29(1), 3-20.

Carpenter, T. P., \& Moser, J. M. (1979). An investigation of the learning of addition and subtraction, theoretical paper no. 79. Madison, WI: Wisconsin Research and Development Center for Individual Schooling.

Fung, M. G., \& Latulippe, C. L. (2010). Computational estimation. Teaching Children Mathematics, 17(3), 170-176.

Fuson, K. C., Wearne, D., Hiebert, J. C., Murray, H. G., Human, P. G., Olivier, A. I., \& Fennema, E. (1997). Children's conceptual structures for multidigit numbers and methods of multi-digit addition and subtraction. Journal for Research in Mathematics Education, 28(2), 130-162.

Fuson, K. (1982). An analysis of the counting-on procedure in addition. In T.P Carpenter, J. M. Moser, \& T. A. Romberg (Eds.), Addition and subtraction: A cognitive perspective. Mahwah, NJ: Erlbaum.

Heirdsfield, A. M., \& Lamb, J. (2006). Teacher actions: Enhancing the learning of mental computation in year 2. In J. Novotná, H. Moraová, M. Krátká, \& N. Stehlíková (Eds.). Proceedings 30th Conference of the International Group for the Psychology of Mathematics Education (Vol. 3, pp. 281-288). Prague, Czech Republic: PME.

Heirdsfield, A. M. (2003). "Spontaneous" mental computation strategies. In N. A. Pateman, B. J. Dougherty, J. T. Zilliox (Eds.). Proceedings of the 27th Conference of the International Group for the Psychology of Mathematics Education (pp. 55-62). Honolulu, HI: University of Hawaii.

Heirdsfield, A. M., \& Cooper, T. J. (2002). Flexibility and inflexibility in accurate mental addition and subtraction: Two case studies. Journal of Mathematical Behavior, 21, 57-74.

Klein, A. S., \& Beishuizen, M. (1998). The empty number line in Dutch second grades: Realistic versus gradual program design. Journal for Research in Mathematics Education, 29(4), 443-464.

Magliaro, S. G., Lockee, B. B., \& Burton, J. K. (2005). Direct instruction 

B. Wood, E. E. Turner, M. Civil, \& J. A. Eli (Eds.). Proceedings of the 38th annual meeting of the North American Chapter of the International Group for the Psychology of Mathematics Education (p. 203). Tucson, AZ: The University of Arizona.

Thompson, I. (2000). Mental calculation strategies for addition and subtraction: Part 2. Mathematics in School, 29(1), 24-26.

Thompson, I. (1999a). Getting your head around mental calculation. In I. Thompson (Ed.). Issues in teaching numeracy in primary schools (pp. 145-156). Buckingham, UK: Open University Press.

Thompson, I. (1999b). Mental calculation strategies for addition and subtraction: Part 1. Mathematics in School, 28(5), 2-4.

Threlfall, J. (2002). Flexible mental calculation. Educational Studies in Mathematics, 50(1), 29-47.

Tsao, Y. (2011). The study of number sense and teaching practice. Journal of Case Studies in Education, 2, 1-14.

Van den Heuvel-Panhuizen, M. (2001). Realistic mathematics education in the Netherlands. In J. Anghileri (Ed.). Principles and practices in arithmetic teaching (pp. 49-64). Buckingham, UK: Open University Press.

Vygotsky, L. S. (1978). Mind in society: The development of higher psychological processes. Cambridge, MA: Harvard University Press.

Wood, D., Bruner, J., \& Ross, G. (1976). The role of tutoring in problem solving. Journal of Child Psychology and Child Psychiatry, 17, 89-100.

Yackel, E. (2001). Perspectives on arithmetic from classroom-based research in the United States of America. In J. Anghileri (Ed.). Principles and practices in arithmetic teaching (pp. 15-32). Buckingham, UK: Open University Press.

Yang, D. C. (2007). Investigating the strategies used by pre-service teachers in Taiwan when responding to number sense questions. School Science and Mathematics, 107(7), 293-301.

Young-Loveridge, J., Bicknell, B., \& Mills, J. (2012). The mathematical content knowledge and attitudes of New Zealand pre-service primary teachers. Mathematics Teacher Education and Development, 14(2), 2849.

\section{Authors:}

Sayonita Ghosh Hajra

University of Utah (Currently, at Hamline University, Saint Paul, MN)

Email: sghoshhajra01@ @amline.edu

Victoria Kofman

Stella Academy

Email:drkofman@gmail.com 